\title{
BMJ Open Cross-sectional analysis of US scope of practice laws and employed physician assistants
}

To cite: Valentin VL, Najmabadi S, Everett C. Crosssectional analysis of US scope of practice laws and employed physician assistants. BMJ Open 2021;11:e043972. doi:10.1136/ bmjopen-2020-043972

- Prepublication history and additional online supplemental material for this paper are available online. To view these files, please visit the journal online (http://dx.doi.org/10. 1136/bmjopen-2020-043972)

Received 20 August 2020 Revised 06 March 2021 Accepted 15 April 2021

Check for updates

(C) Author(s) (or their employer(s)) 2021. Re-use permitted under CC BY-NC. No commercial re-use. See rights and permissions. Published by BMJ.

${ }^{1}$ Department of Family and Preventive Medicine, University of Utah, Salt Lake City, Utah, USA

${ }^{2}$ Community and Family Medicine, Duke University, Durham, North Carolina, USA

Correspondence to Dr Shahpar Najmabadi; s.najmabadi@utah.edu

\section{ABSTRACT}

Objective This study examined if the variation in physician assistant (PA) state scope of practice (SOP) laws across states are associated with number of employed PAs, PA demographics and PA/population ratio per state. The hypothesis was that less restrictive SOP laws will increase the demand for PAs and the number of PAs in a state.

Design Retrospective cross-sectional analysis at three time points: 1998, 2008, 2017.

Setting Fifty states and the District of Columbia. Participants Employed PAs in 1998, 2008, 2017. Methods SOP laws were categorised as permissive, average and restrictive. Three national datasets were combined to allow for descriptive analysis of employed PAs by year and SOP categories. We used linear predictive models to generate and compare PA/population ratio least square means by SOP categories for each year. Models were adjusted for percent female PA and PAs mean age. Results There was a median PA/population ratio of 23 per 100000 population in 1998 and 33 in 2017. A heterogeneous expansion of SOP laws was seen with 17 states defined as super expanders while 15 were never adopters. In 2017, comparing restrictive to permissive states showed that in adjusted models permissive SOP laws were associated with 11.7 (p .03) increase in ratio of employed PAs per 100000 population, demonstrating that states with permissive SOP laws have an increased PA density.

Conclusions There has been steady growth in the mean $\mathrm{PA} /$ population ratio since the turn of the century. At the same time, PA SOP laws in the USA have expanded, with just 10 states remaining in the restrictive category. Permissive SOP laws are associated with an increase in the ratio of employed PAs per state population. As states work to meet the projected physician need, SOP expansion may be an important policy consideration to increase the PA workforce.

\section{INTRODUCTION}

The Association of American Medical Colleges projects a shortage of 46900 to 121900 physicians by 2032. ${ }^{1}$ Analysis of workforce supply and demand at the state level reveals that this shortage will likely be distributed unequally; some states have a lower supply of providers than others, rural shortages tends to be worse than urban settings, and some specialties are

\section{Strengths and limitations of this study}

Data from the Bureau of Labor and Statistics (BLS) provided employed physician assistants (PAs) census data for all employed PAs from 1998, 2008 and 2017 for all 50 states and the District of Columbia.

- Comprehensive state legislative Scope of Practice (SOP) data from the American Academy of PAs was cross referenced and verified for each state and each year and then combined with the annual employment data from the BLS.

- This is the first study analysing two decades of national PA employment for all 50 states and the District of Columbia across three time points to describe the effect of state SOP laws on PAs.

- The analysis did not include other possible confounding variables that may impact PA employment numbers, including physician or nurse practitioner employment numbers or state and federal healthcare legislative policies.

- The analysis was unable to account for lag time in terms of when the SOP laws were passed and the PA employment occurred.

in greater demand than others. ${ }^{2-4}$ Increased use of physician assistants (PAs) is one potential solution that has been proffered to address the current and anticipated deficiency. ${ }^{5-8}$ One important factor that can facilitate or restrict the capacity of PAs to fill the provider shortage is state scope of practice (SOP) laws. ${ }^{910}$

Research indicates that favourable SOP legislation is associated with an increase in the supply of healthcare providers. ${ }^{11}$ A number of previous studies have demonstrated that the supply of PAs and nurse practitioners (NPs) within a state is inversely related with the restrictiveness of SOP laws. ${ }^{9-12}$ In 2010, the Institute of Medicine report on the Future of Nursing recommended full SOP for nurses, which became the catalyst for SOP expansion for NPs. ${ }^{18}$ While striving to work at the top of their licence, NPs have shown that restrictions on SOP is associated with reduced growth and number of available NPs in communities. ${ }^{10}$ 
One 2009 study of PAs noted that SOP laws may effect $\mathrm{PA} /$ population ratio by state but to date, the effect of SOP on PA employment has not been clearly delineated. ${ }^{9}$

Throughout the decades, PAs have worked at the state level to push for expansion of PA practice laws to decrease the barriers to providing patient care. These efforts occur state by state with, for example, 45 states in 2019 passing legislation to amend SOP laws for PAs. ${ }^{19}$ Despite this work, there remains wide variation in PA SOP laws in the USA, ranging from highly restrictive to top-of-license practice. ${ }^{9}{ }^{20}$ In support of top-of-license practice, in 2017, the American Academy of PAs (AAPA) moved to adopt optimal team practice (OTP), this proposed practice act is intended to further increase the autonomy of PAs. ${ }^{21}$ The tenets of OTP include eliminating a legal requirement for a specific relationship with a physician, creating a separate majority-PA board to regulate PAs, and authorise PAs to directly bill for services. ${ }^{22}$

Fifty years since the inception of the PA profession, there has been a demographic shift from predominantly male to majority female and from largely primary care providers to specialists. ${ }^{23}{ }^{24}$ At the same time, the profession remains young with the median age of employed PAs remaining steady at 38 years old since $2012 .{ }^{25}$ It is unknown if this demographic shift is due, at least in part, to changes in SOP laws. The purpose of this study was to examine whether, and to what degree, variation in PA state SOP laws across states are associated with (1) number of employed PAs per state; (2) PA demographics and (3) PA/population ratio per state. The hypothesis was that restrictive SOP laws limit the demand for PAs, with subsequent impacts on the PA workforce, while less restrictive SOP laws will increase the demand for PAs and therefore the number of PAs in a state.

\section{METHODS}

To assess the association of state SOP laws and PA/population ratio, we used a cross-sectional design to demonstrate the change over a 20-year period through providing 10-year snapshots at three time points of 1998, 2008 and 2017. This work builds on previous work by Valentin $e t$ $a l^{26}$, assessing the impact of PA SOP laws on PA education. We used three SOP categories permissive, average and restrictive, based on the number of PA SOP Key Elements which builds on prior work by Wing et $a l^{1726}$.

\section{Data sources and setting}

Data were obtained from the Bureau of Labor and Statistics (BLS), AAPA census and the AAPA database on PA legislative history for all 50 states and the District of Columbia for the years 1998, 2008 and 2017. The three datasets were combined to allow for analysis of the years of 1998, 2008 and 2017. ${ }^{27}$

\section{Sample/participants}

The combined state/year dataset $(\mathrm{N}=153)$ included number of employed PAs in each state (50 states and
District of Columbia for 3 time points) from the BLS, PA demographics from the AAPA census and state SOP laws from AAPA legislative history. Response rates for AAPA census report was unknown for $1998,34.5 \%$ in 2008 and $10.2 \%$ in 2017.

\section{Variables}

Data from BLS provided the number of PAs employed by state and by year. ${ }^{27} \mathrm{PA}$ ratio was then calculated as: (employed PA in that year/state population in year) ${ }^{28-30}$ $\times 100000$. When comparing $\mathrm{PA} /$ population ratio over time the researchers defined states as super expanders, contractors, slow expanders and never adopters. Super expanders are defined as states with at or above the median ratio in 1998 and remained at or above the median in 2017. Contractors are defined as states with at or above the median ratio in 1998 and fell below the median in 2017. Slow expanders are defined as states with below the median in 1998 and rose to at or above the median PA/population ratio by 2017 . Never adopters are defined as states with below the median PA/population ratio in 1998 and remained below in 2017.

The AAPA established the permissive PA practice act which includes the six key elements of a modern PA practice Act: (1) licensure as a regulatory term, (2) full prescriptive authority, (3) scope of practice determined at the practice level, (4) adaptable collaboration requirements, (5) cosignature requirements determined at the practice level and (6) number of PAs a physician may collaborate with determined at the practice level. ${ }^{31}$ Data from AAPA included which six key elements were approved in each state by year and the total number of six key elements was calculated. Consistent with prior research, each state was categorised into one of three SOP groups based on the number of key elements adopted: permissive SOP (5-6 elements), average SOP (3-4 elements) and restrictive SOP (0-2 elements). ${ }^{17}$ The AAPA census provided mean age and mean female gender. Mean age and female gender was weighted by number of PAs employed in each state. There were no missing data for the number of key elements, mean age or mean gender. For number of employed PAs in 2008 there was missing data for California and Pennsylvania. Missing data for 2008 were imputed by taking the average of the number of PAs from 2007 and 2009.

\section{Statistical analysis}

Descriptive statistics were used to demonstrate the geographic location and change in the number of states categorised as permissive, average and restrictive SOP with the PA/population ratio for each state for the years of 1998 and 2017 and presented visually with maps (figures 1 and 2). The change in $\mathrm{PA} /$ population ratio per state over the time period relative to the median $\mathrm{PA} /$ population ratio for the nation was determined and presented visually with a map (figure 3 ). Descriptive statistics by year and SOP categories was determined including number of 


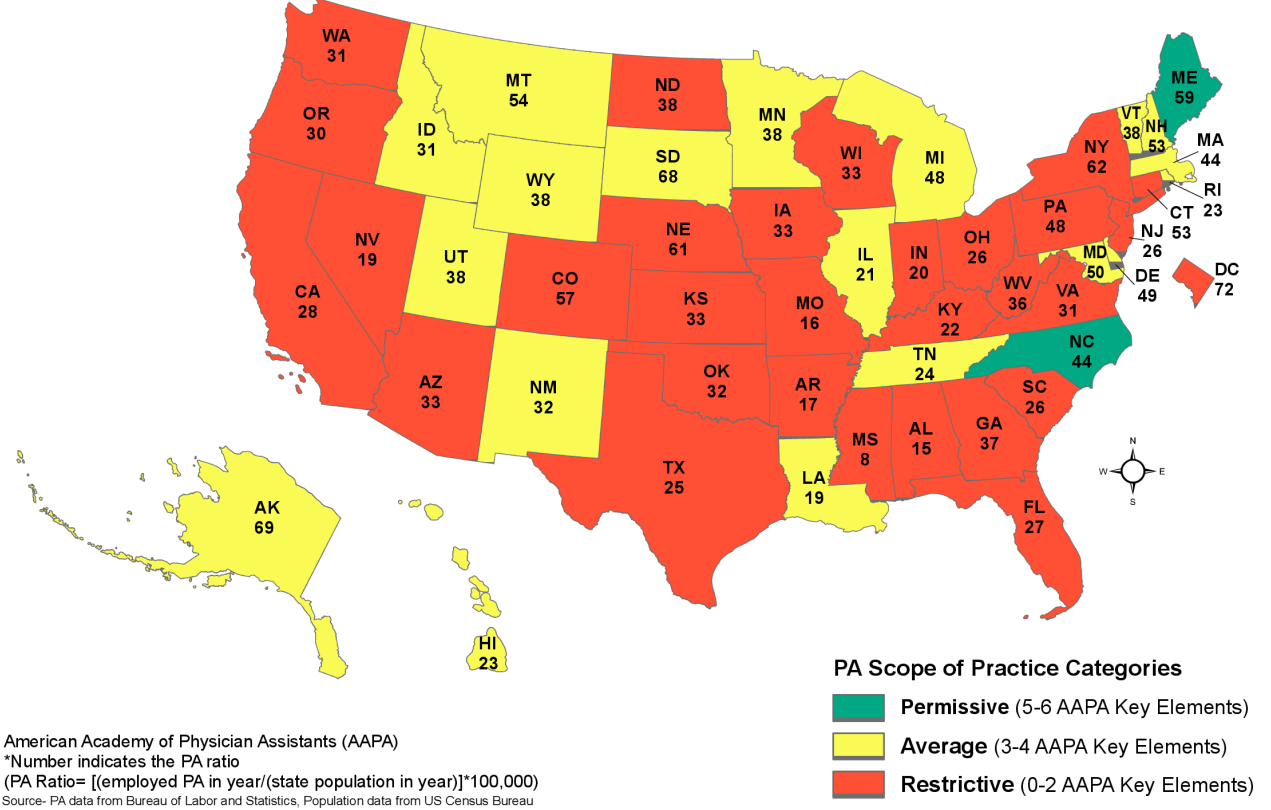

Figure 1 Number of physician assistants (PAs) per 100000 population and PA scope of practice categories: USA, 1998.

states, number of employed PAs, percent of female PAs and mean age of PAs.

We used unadjusted survey linear regression models to generate least squares mean $(95 \% \mathrm{CI})$ of age and percent of female PAs for each SOP level, incorporating weights to account for state-level differences in PA population demographics. Linear mixed models were used to generarte and compare least squares mean of $\mathrm{PA} /$ population ratio by SOP categories, with restrictive as the reference for the years of 1998, 2008 and 2017. All analyses were conducted using SAS V.9.4.

\section{RESULTS}

Over the study period, the number of states in the permissive SOP category increased, as did the PA ratio. The number of permissive states increased from 2 in 1998 to 7 in 2008 and 16 by 2017, while the restrictive states went from 30 in 1998 to 20 in 2008 and 10 in 2017. (See figures 1 and 2) In 1998 the median PA/population ratio was 23 PAs per 100000 population and 33 per 100000 in 2017. Figure 3 shows that 17 states are defined as super expanders while 9 states are contractors, 10 are slow expanders and 15 are never adopters (see online

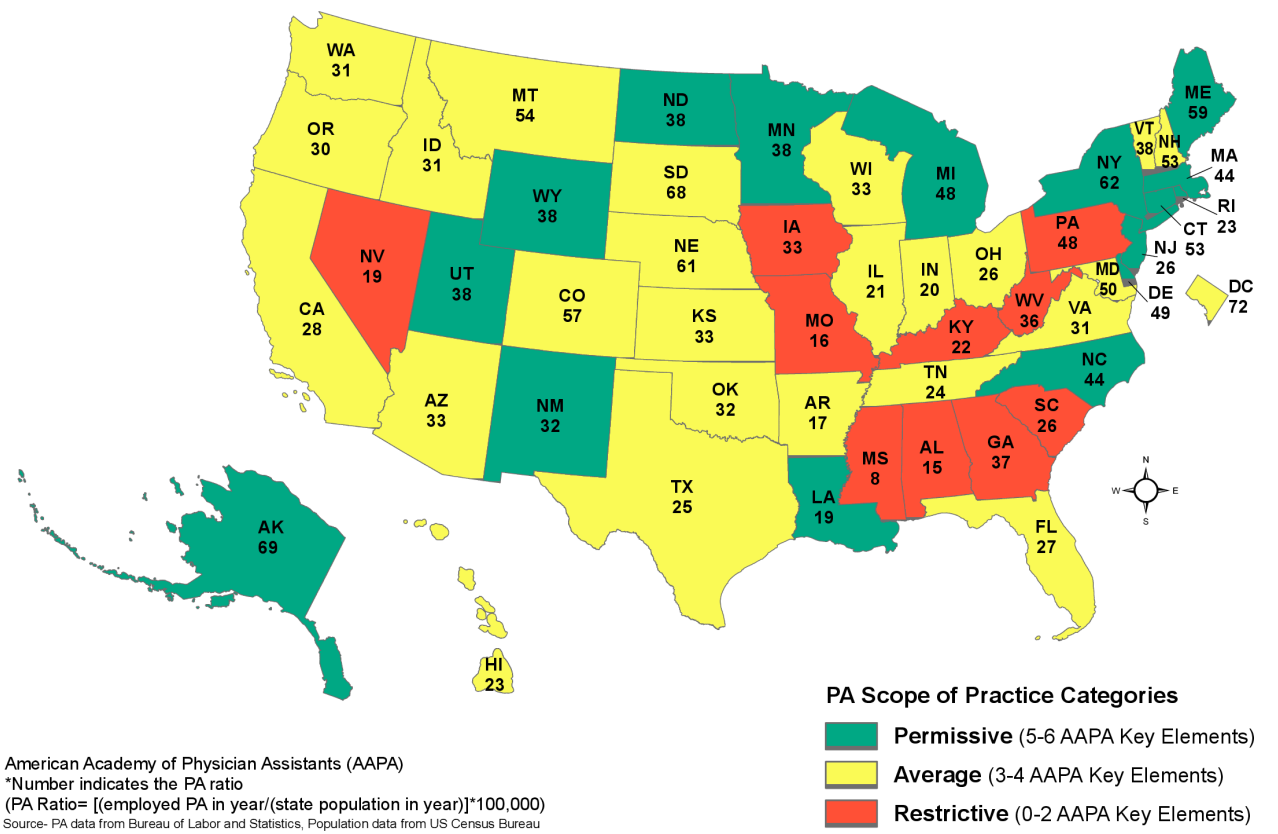

Figure 2 Number of physician assistants (PAs) per 100000 population and PA scope of practice categories: USA, 2017. 


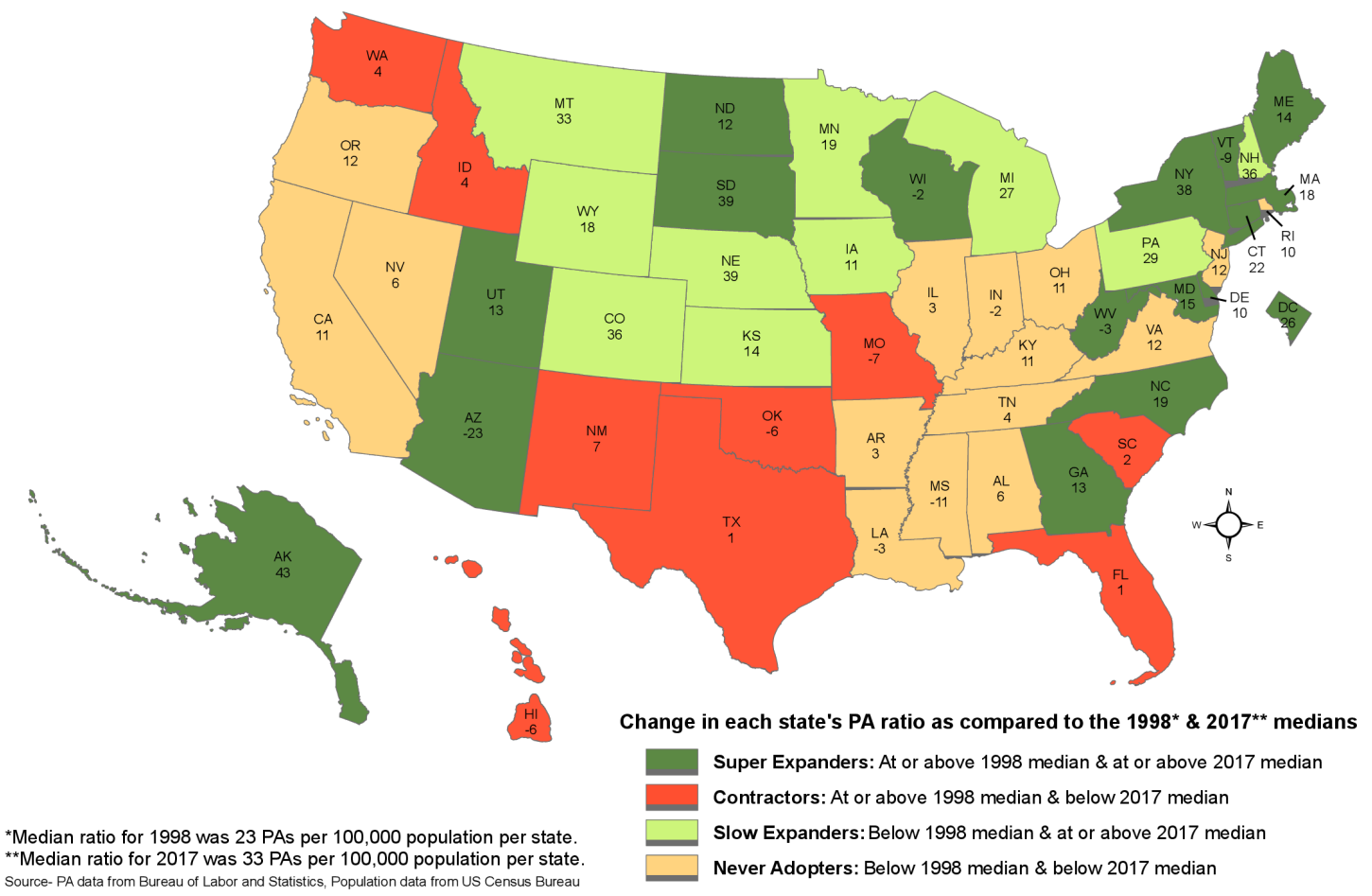

Figure 3 Change in state ratio of physician assistants (PAs) per 100000 population from 1998 to 2017.

supplemental table 1 for $\mathrm{PA} /$ population ratio of each state)

Since 1998, the number of PAs in the USA has grown from 61980 employed PAs to 109200 in 2017 (see table 1). Of interest, in $199873.4 \%$ of PAs were employed in a restrictive SOP state which decreased to $39.7 \%$ in 2008 and $15.1 \%$ by 2017 . As of 2017 , the majority of PAs $(51.9 \%)$ are employed in average states with $33.0 \%$ employed in permissive states.

There is no association between percent PA gender and SOP categories in the selected years. Over the study period, the state total mean number of PAs increased, while the mean percent of female PAs in permissive states increased from $48.2 \%$ in 1998 to $68.3 \%$ in 2017 . No association is seen between SOP categories and age (see table 1). Meanwhile, the mean age of employed PAs remained steady at 40-41 years old across all time points.

Table 2 presents the associations between unadjusted and adjusted PA/population ratio and SOP categories. States with permissive and average SOP laws compared with restrictive states in 1998 did not differ significantly in their PA/population ratio. However, in 2008, in unadjusted models, comparing restrictive to average, and restrictive to permissive states was associated with 10.6 ( $\mathrm{p} .03$ ) and 15.1 ( $\mathrm{p} .03$ ) increase in ratio of employed PAs per 100000 population. In the adjusted models still compared with restrictive states, the average states had 9.4 (p .04) higher ratio. In the year 2017, comparing restrictive to permissive states was associated with 16.5 ( $\mathrm{p} .01$ ), and 11.7 ( p .03) increase in ratio of employed PAs per 100000 population, in unadjusted and adjusted models, respectively.

\section{DISCUSSION}

This is the first study to demonstrate that states with permissive SOP laws have an increased PA density. In 2017, states with permissive SOP had 43 PAs per 100000 population while restrictive states had 26 PAs per 100000 people. The PA/population ratio remained higher in permissive states compared with restrictive at each time point with this difference in ratio increasing over time from 11.2 in 1998 to 16.5 in 2017. This finding suggests that restrictive SOP laws limit demand for PAs and therefore limit supply. This outcome is similar to research on NPs where restrictions on SOP have been noted to affect productive capacity and provider supply. ${ }^{15}$ This study shows a decrease in PA supply in states with restrictive SOP laws compared with states with permissive SOP laws, which may be from a lack of demand but this is not clear. Further investigation is needed to determine if a specific SOP key element is associated with PA employment numbers. Also, future research at the state level is needed to understand the possible interplay of state SOP laws and organisational policy.

Over the study period, there has been a decrease in the number of states with restrictive SOP laws, with a resulting change in the number of employed PAs from majority restrictive states to average and permissive states. These results expand the findings of Wing $e t a l$ and Gadbois $e t$ $a l$ that PA SOP laws continue to expand and vary widely by state. ${ }^{1732}$ As of 2017,16 states have permissive practice laws, but the majority of states remain with average SOP, while 10 still have restrictive. This leaves a heterogeneity in state SOP laws with only $15 \%$ of PAs employed in a restrictive SOP states as of 2017. It is unclear if PAs are 

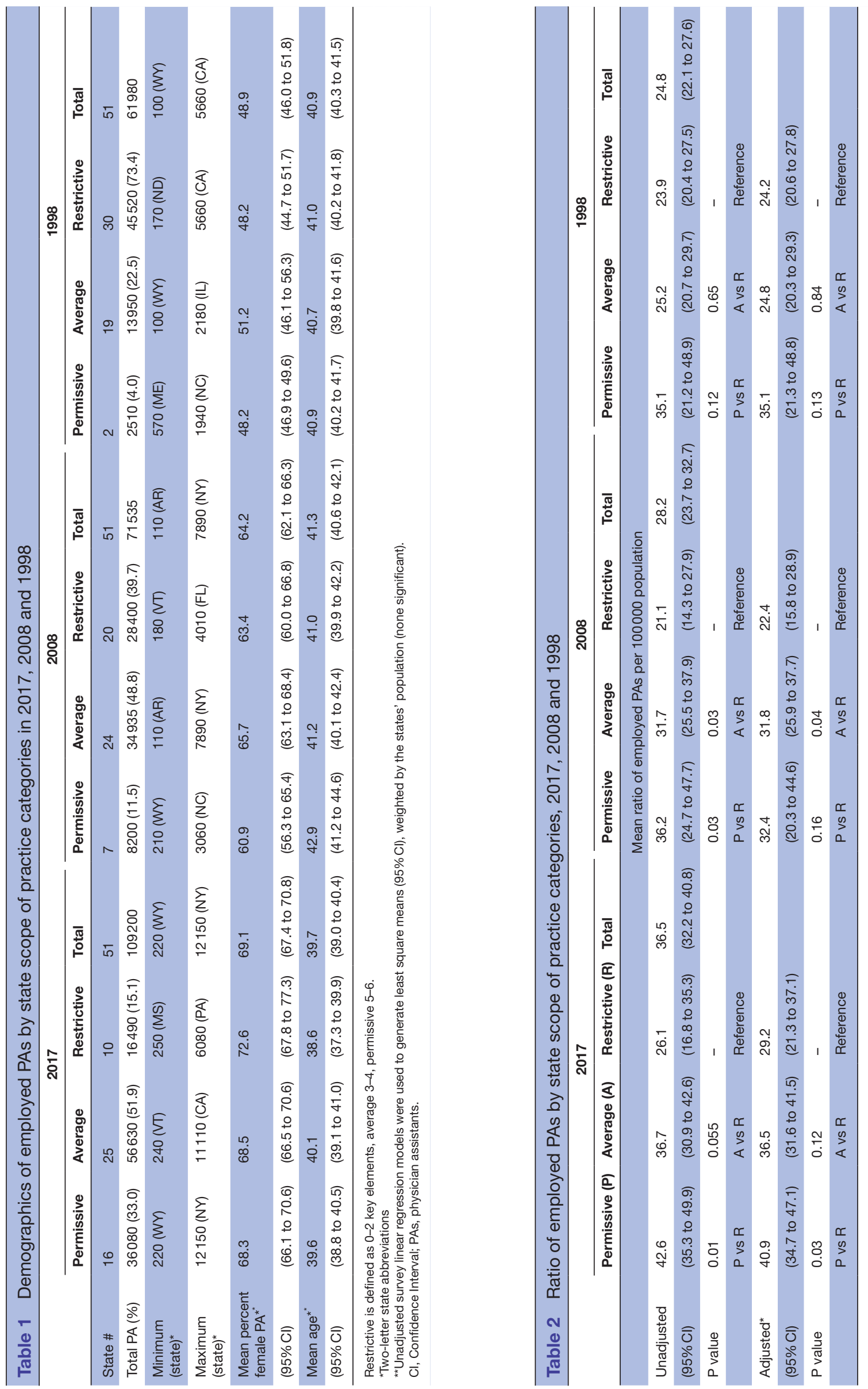
moving away from restrictive SOP states or if there is a lack of demand to draw them to these states. With the majority of employed PAs in average or permissive states, it is understandable why the constituents of pushed for AAPA to change its policy to recommend OTP with a desire for increased practice autonomy. Research needs to focus on the impact that this expanded autonomy has on PA employment on both the expanded practice states and the restrictive practice states.

As there have been decades of SOP expansion and growth in the number of PAs, the median PA/population ratio has also risen. However, as of 2017 half of US states are defined as contractors or never adopters which demonstrates that PA policy makers still have a long road ahead to assure that all PAs are working within the full scope of their license. It is unclear if NPs or physicians are filling this provider gap. A recent study found that by expanding SOP laws for both PAs and NPs, the primary care workforce capacity increased particularly in rural areas, but that this change was limited. ${ }^{33}$ As states work to address the projected physician shortage, the findings of this study are consistent with the hypothesis that SOP expansion will increase the PA workforce in a state. This finding allows for future research to examine the difference in patient access and health outcomes by state and $\mathrm{PA} /$ population ratio in the United States. Work by Pittman $e t a b^{4}$ argues that SOP laws were not associated with hospital privileges and that within one state there was significant variation. The findings of this study support our hypothesis that states with expanded SOP laws have a higher demand for PAs and therefore a higher number of employed PAs. This sheds some light on state to state variations in employment but more research is needed to understand the countless factors at play at the state level in the supply and demand for PAs.

\section{Limitations}

This study has a number of important limitations. First, we analysed cross-section data at three time points, which may limit generalisability of the findings. However, to gain an understanding of causation, longitudinal analysis needs to be undertaken. Second, the low annual response rate for the AAPA data on PA demographics which was unknown in 1998 and ranged from 35\% to $10 \%$ for the other time points may lead to a sampling bias towards or away from the null. Third, this analysis did not include other possible confounding variables that may impact PA employment numbers, including physician or NP employment numbers, or state and federal healthcare legislative policies. Fourth, we were unable to account for lag time in terms of when the SOP laws were passed and the PA employment occurred. Fifth, the categorisation of SOP elements in three categories considers each element to be equal and interchangeable which is unlikely. Future research should consider each element individually and the impact on employement. These limitations are counterbalanced by a number of important strengths, including the robust SOP data provided by AAPA that was cross referenced and verified for each state and each year combined with annual employment data from the BLS.

\section{CONCLUSIONS}

PA SOP laws in the USA have expanded since the turn of the century, with most states with average SOP, and 10 states remaining in the restrictive category. Meanwhile, there has been steady growth in the mean PA/population ratio from 23 to 33 per 100000 population over the same two decades. States with permissive SOP laws have an average of 16.5 more PAs per 100000 population compared with a state with restrictive SOP laws. As states work to meet the projected physician shortage, this study supports the principle that SOP expansion may be an important lever to assist with increasing the PA workforce in a state. Future research needs to incorporate a longitudinal analysis with lag times to understand if specific key elements impact PA employment and the timeframe of that impact.

Acknowledgements Acknowledgement of Marissa Taddie for the expertise she provided in developing the maps for this work.

Collaborators None.

Contributors VLV, SN and CE were involved in the data analysis, interpretation, drafting the manuscript and reviewed/edited the manuscript.

Funding This project was funded by a grant award from the Physician Assistant Education Association, Washington, DC and the American Academy of Physician Assistants, Alexandria, VA. Grant number: N/A.

Disclaimer Funding of this project does not necessarily constitute an endorsement of the findings of this research report by either organisation.

Map disclaimer The depiction of boundaries on the map(s) in this article does not imply the expression of any opinion whatsoever on the part of BMJ (or any member of its group) concerning the legal status of any country, territory, jurisdiction or area or of its authorities. The map(s) are provided without any warranty of any kind, either express or implied.

\section{Competing interests None declared.}

Patient consent for publication Not required.

Ethics approval As we used publicly available BLS data, and the requested AAPA data does not contain identifying variables, this study was determined exempt from review by the University of Utah Institutional Review Board (IRB 00107271).

Provenance and peer review Not commissioned; externally peer reviewed.

Data availability statement BLS has a public use linkage to access Labor Statistics data 1998-2017. The data from AAPA on PA census and legislative history was requested through AAPA research department.

Supplemental material This content has been supplied by the author(s). It has not been vetted by BMJ Publishing Group Limited (BMJ) and may not have been peer-reviewed. Any opinions or recommendations discussed are solely those of the author(s) and are not endorsed by BMJ. BMJ disclaims all liability and responsibility arising from any reliance placed on the content. Where the content includes any translated material, BMJ does not warrant the accuracy and reliability of the translations (including but not limited to local regulations, clinical guidelines, terminology, drug names and drug dosages), and is not responsible for any error and/or omissions arising from translation and adaptation or otherwise.

Open access This is an open access article distributed in accordance with the Creative Commons Attribution Non Commercial (CC BY-NC 4.0) license, which permits others to distribute, remix, adapt, build upon this work non-commercially, and license their derivative works on different terms, provided the original work is properly cited, appropriate credit is given, any changes made indicated, and the use is non-commercial. See: http://creativecommons.org/licenses/by-nc/4.0/. 


\section{ORCID iDs}

Virginia L Valentin http://orcid.org/0000-0002-9126-6650

Shahpar Najmabadi http://orcid.org/0000-0003-1247-8848

\section{REFERENCES}

1 AAMC. The complexities of physician supply and demand: projections from 2017-2032, 2019. Available: https://aamc-black. global.ssl.fastly.net/production/media/filer_public/31/13/3113ee5ca038-4c16-89af-294a69826650/2019_update_-_the_complexities of_physician_supply_and_demand_-_projections_from_2017-2032. pdf

2 HRSA. National and regional projections of supply and demand for internal medicine subspecialty practitioners: 2013-2025, 2016. Available: ttps://bhw.hrsa.gov/sites/default/files/bureau-healthworkforce/data-research/internal-medicine-subspecialty-report.pdf

3 DHHS. State-level projections of supply and demand for primary care practitioners: 2013-2025, 2016. Available: https://bhw.hrsa.gov/ sites/default/files/bureau-health-workforce/data-research/primarycare-state-projections2013-2025.pdf

4 Fraher E, Brandt B. Toward a system where workforce planning and interprofessional practice and education are designed around patients and populations not professions. J Interprof Care 2019;33:389-97.

5 Auerbach DI, Chen PG, Friedberg MW, et al. Nurse-managed health centers and patient-centered medical homes could mitigate expected primary care physician shortage. Health Aff 2013;32:1933-41.

6 Fraher E, Machta R, Halladay J. The workforce transformations needed to staff value-based models of care. Sheps center for health services research, 2015. Available: http://www.shepscenter.unc. edu/wp-content/uploads/2015/12/DataBrief_ValueBasedWorkforce_ FraherMachtaHalladay_final.pdf

7 KFF. Improving access to adult primary care in Medicaid: exploring the potential role of nurse practitioners and physician assistants, 2011. Available: https://www.kff.org/medicaid/issue-brief/improvingaccess-to-adult-primary-care-in/

8 McMichael BJ. Beyond physicians: the effect of licensing and liability laws on the supply of nurse practitioners and physician assistants. $J$ Empir Leg Stud 2018;15:732-71.

9 Sutton JP, Ramos C, Lucado J. US physician assistant (PA) supply by state and County in 2009. J Am Acad Physician Assist 2010;23:E5-8.

10 Wiler JL, Rooks SP, Ginde AA. Update on midlevel provider utilization in U.S. emergency departments, 2006 to 2009. Acad Emerg Med 2012;19:986-9.

11 Sekscenski ES, Sansom S, Bazell C, et al. State practice environments and the supply of physician assistants, nurse practitioners, and certified nurse-midwives. $N$ Engl J Med 1994;331:1266-71.

12 Glicken AD, Miller AA. Physician assistants: from pipeline to practice. Acad Med 2013;88:1883-9.

13 Hing E, Hsiao C-J, Chun-Ju H. In which states are physician assistants or nurse practitioners more likely to work in primary care? JAAPA 2015;28:46-53.

14 Kuo Y-F, Loresto FL, Rounds LR, et al. States with the least restrictive regulations experienced the largest increase in patients seen by nurse practitioners. Health Aff 2013;32:1236-43.
15 Reagan PB, Salsberry PJ. The effects of state-level scope-ofpractice regulations on the number and growth of nurse practitioners. Nurs Outlook 2013;61:392-9.

16 Willis J. Barriers to PA practice in primary care and rural medically underserved areas. JAAPA 1993;6:418-22.

17 Wing $\mathrm{P}$, Langelier $\mathrm{MH}$, Salsberg ES, et al. The changing professional practice of physician assistants: 1992 to 2000. JAAPA 2004;17:3740, 42, 45-39.

18 IOM. The future of nursing: leading change, advancing health. Washington, DC: National Academies Press, 2011.

19 Walker C. 2016 was another banner year for PAS at the state level, 2019. Available: https://www.aapa.org/news-central/2020/01/pascelebrate-a-year-of-unprecedented-wins-at-the-state-level/

20 Timmons EJ. The effects of expanded nurse practitioner and physician assistant scope of practice on the cost of Medicaid patient care. Health Policy 2017;121:189-96.

21 Sobel J. Seven things you should know about optimal team practice. JAAPA 2019;32:12-13.

22 AAPA. What is optimal team practice? 2017. Available: https://www. aapa.org/advocacy-central/optimal-team-practice/

23 Morgan P, Everett C, Humenick K, et al. Specialty choice among US physician assistants: distribution, salaries, and comparison to physicians. JAAPA 2016;29:46-52.

24 Smith DT, Jacobson CK. Racial and gender disparities in the physician assistant profession. Health Serv Res 2016;51:892-909.

25 NCCPA. Statistical profile of certified physician assistants: an annual report of the National Commission on certification of physician assistants, 2018. Available: https://prodcmsstoragesa.blob.core. windows.net/uploads/files/2018StatisticalProfileofCertifiedPhysici anAssistantsbyState.pdf

26 Valentin VL, Najmabadi S, Jones J, et al. State scope of practice laws: an analysis of physician assistant programs and graduates. $J$ Physician Assist Educ 2020;31:179-84.

27 BLS. Occupational employment and wages, may 2018: 29-1071 physician assistants, 2018. Available: https://www.bls.gov/oes/ current/oes291071.htm\#st

28 census.gov. Annual estimates of the resident population for the United States, regions, states, and Puerto Rico: April 1, 2010 to July 1, 2019 (NST-EST2019-01), 2019. Available: census.gov

29 census.gov. Intercensal estimates of the resident population for the United States, regions, states, and Puerto Rico: April 1, 2000 to July 1, 2010 (ST-ESTOOINT-01), 2019. Available: census.gov

30 census.gov. State and County intercensal tables: 1990-2000, 2016 Available: https://www.census.gov/data/tables/time-series/demo/ popest/intercensal-1990-2000-state-and-county-totals.html

31 AAPA. The six key elements of a modern PA practice act, 2016. Available: https://www.aapa.org/wp-content/uploads/2016/12/Issue Brief_Six_Key_Elements.pdf

32 Gadbois EA, Miller EA, Tyler D, et al. Trends in state regulation of nurse practitioners and physician assistants, 2001 to 2010. Med Care Res Rev 2015;72:200-19.

33 Graves JA, Mishra P, Dittus RS, et al. Role of geography and nurse practitioner Scope-of-Practice in efforts to expand primary care system capacity: health reform and the primary care workforce. Med Care 2016;54:81-9.

34 Pittman P, Leach B, Everett C, et al. NP and PA Privileging in acute care settings: do scope of practice laws matter? Med Care Res Rev 2020;77:112-20. 